\title{
Temporary marking of unweaned southern elephant seal (Mirounga leonina L.) pups
}

\author{
P.J. Nico de Bruyn*, Cheryl A. Tosh, W. Chris Oosthuizen, \\ Mashudu V. Phalanndwa \& Marthán N. Bester \\ Mammal Research Institute, Department of Zoology and Entomology, University of Pretoria, Pretoria, 0002 South Africa \\ Received 27 February 2008. Accepted 27 May 2008
}

\begin{abstract}
Like many pinniped species, southern elephant seals (Mirounga leonina) are conducive to long-term population studies using mark-recapture techniques. The twenty-four year longitudinal dataset at sub-Antarctic Marion Island has already provided much insight into elephant seal population dynamics. However, a limitation of the present dataset is that mother/pup relatedness cannot be examined because pups are only tagged after their tagged mothers have abandoned them. We test the usefulness of two different temporary marking techniques (tagging and 'strapping'), and four different marker types over two consecutive breeding seasons for use on pups with attending marked mothers. We show that strapping is an ineffective way to mark unweaned southern elephant seals. By comparison, 'Supersmall ${ }^{\circledR}$, Dalton plastic tags allow quick, effective and easy marking of large numbers of pups with known mothers, without excessive marker loss.
\end{abstract}

Key words: Marion Island, mark-recapture, marker types, Mirounga leonina, pinnipeds, phocids.

\section{INTRODUCTION}

The major objective in studies of population dynamics is to detect and analyse differences in life history traits among groups of individuals through temporal and spatial scales (Lebreton et al. 1992). Such differences affect rates of population change through variations in survival and fecundity (Siniff et al. 1977). Longitudinal life history studies (Clobert et al. 1994) require sufficiently large marked/known-age samples of a given population to allow for analysis of age structure and demography (Erickson et al. 1993). At Marion Island, a total of 11830 (average: 473 annually, range: $389-700$ ) southern elephant seal (Mirounga leonina L.) pups were double-tagged in their hind-flippers immediately after/at weaning from 1983 to 2007. A great deal of research has been aimed at demographic aspects of the southern elephant seal population at Marion Island owing to this longitudinal dataset (1983-present) (e.g. Bester \& Wilkinson 1994; Pistorius et al. 2004; McMahon et al. 2005). However, analyses investigating the mother-pup relationships (e.g. first year survival related to mother age) cannot be undertaken because pups are tagged only after the maternal bond has been severed (weaning) and thus the mothers' identity becomes anonymous.

\footnotetext{
*To whom correspondence should be addressed.
}

E-mail: pjndebruyn@zoology.up.ac.za
In addition, the polygynous breeding system of this species, i.e. the formation of a 'harem' of cows on a beach defended by at least one adult bull (beachmaster), complicates the marking of a large number of pups before weaning, primarily by making access to the pups dangerous. Also, the disturbance caused in reaching any particular pup disrupts the rest of the harem, causing animals to mingle, resulting in further mother-pup pairs not being easily identifiable. To mark all pups with marked mothers (range: 1-60 pups/harem on Marion Island) at this early stage requires intrusion into the harem and hence disturbance to the adults. We therefore tested four potential methods for quickly marking large numbers of unweaned pups and report on the most effective of these methods to enable accurate identification of mother-pup pairs.

\section{MATERIALS AND METHODS}

\section{Study area}

Marion Island $\left(46^{\circ} 54^{\prime} \mathrm{S}, 37^{\circ} 45^{\prime} \mathrm{E}\right)$ is situated in the Southern Indian Ocean and is approximately $290 \mathrm{~km}^{2}$ in area. Southern elephant seals use the more easily accessible beaches on the eastern and northern shores of the island, which include approximately $60 \mathrm{~km}$ of coastline. 


\section{Data collection}

During the 2006 southern elephant seal breeding season a total of 120 bands were fashioned by stitching the two ends of a $235 \mathrm{~mm}$ (16 mm width) section of ballet elastic (BE16) fabric strip together with a $10 \mathrm{~mm}$ overlap (Fig. 1). During the 2007 breeding season a further 99 bands were made, 53 of which were $20 \mathrm{~mm}$ wide. Regular garment stitching/sewing Polycote ${ }^{\circledast}$ thread was used to attach the two ends of each band and double 'zigzag' stitching provided strong binding but which allowed eventual (after 1.5 months) unravelling/breaking owing to natural wear to avoid entanglement and possible injury to the seals' 'ankle' if the band was not otherwise removed. The inside and outside of each band was inscribed with a unique number using indelible fabric ink (Staedtler ${ }^{\circledR}$ Lumocolor laundry marker) and the same unique number was embroidered (polyester M782 thread) on the outside of the band (Fig. 1). All bands were either white or light pink to improve visibility once attached. Although soiling reduced the sightability of bands, not all bands become soiled thus some advantage was retained by using light coloured elastic. The two band types $(16 \mathrm{~mm}$ and $20 \mathrm{~mm}$ ) were regarded as different marker types.

During the 2007 breeding season we also tested two types of temporary livestock ear-tags, Supersmall ${ }^{\circledast}$ tags and Temptags ${ }^{\circledast}$ (Dalton Supplies Ltd., Henley-on-Thames, U.K.) (Fig. 1). These tags are designed for short-term temporary use on young animals to minimize injury to delicate/soft tissue at the tag site, and as such are not made to withstand natural wear and tear for longer than six months (http://www.dalton.co.za/za/products/ pages_pr/research/r_supers.htm). Forty-seven Supersmall ${ }^{\circledast}$ tags and 48 Temptags $^{\circledR}$ were tested, each type was uniquely numbered from 001 to 047/048 on the outside of outer and inner tag components, while the inside of both components was inscribed with 'Marion Is', the attachment locality. The shape and size of the tag types were distinct. Supersmall ${ }^{\circledast}$ tags were white only and Temptags ${ }^{\circledast}$ were white with a green fixing pin. Supersmall ${ }^{\circledast}$ tags are inserted with an applicator, while Temptags ${ }^{\circledR}$ are inserted by hand. We did not test the application of a single Dalton Jumbotag ${ }^{\circledR}$ to unweaned pups for the following reasons:

(1) Jumbotags ${ }^{\circledast}$ are more robust (for longer lifespan) with a larger piercing pin that causes greater injury to the soft interdigital webbing of unweaned pups.
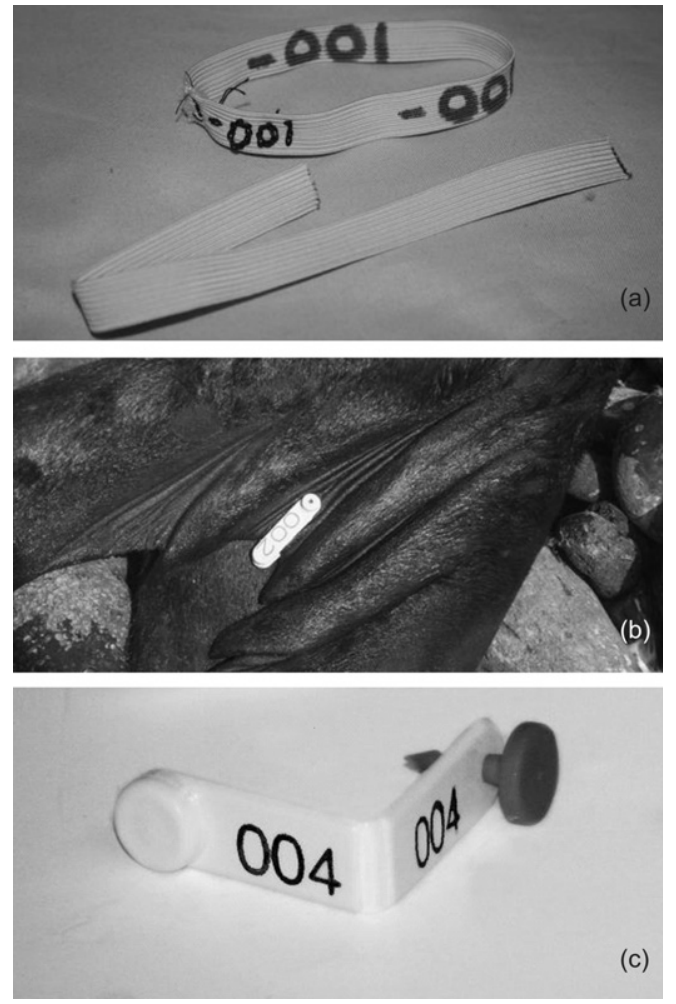

Fig. 1. The different marker types used to identify unweaned southern elephant seal pups at Marion Island. (a) Band markers (Note the embroidered and ink numbers with a dash as pretext to ascertain the numbers' correct orientation), (b) Supersmall ${ }^{\circledR}$ tags placed in the inner inter-digital webbing of the hind flipper of an unweaned pup, and (c) Temptags ${ }^{\circledR}$.

(2) Application of the latter therefore needs to be carefully done to ensure reduced tag loss resulting from incorrect application (Pistorius et al. 2000). Double-tagging of an unweaned pup while at the side of the mother in a harem is difficult and dangerous, because after application of the first tag, the element of surprise is lost.

(3) Given the long-standing (1983-present) and continuing double-tagging regime for weaned pups at Marion Island, single tagging of Jumbotags ${ }^{\circledR}$ would require that the identical remaining Jumbotag ${ }^{\circledR}$ of a pair (for tagging the other flipper) would need to be stored and the correct pup located later/after weaning to insert the correct other tag of the pair. Additionally, this procedure would affect the estimation of tag loss of the Jumbotags ${ }^{\circledast}$, because each tag would have different application dates (Pistorius et al. 2000). 
Table 1. Numbers of different marker types attached on unweaned southern elephant seal pups during the 2006 and 2007 breeding seasons at Marion Island.

\begin{tabular}{|c|c|c|c|c|c|}
\hline \multirow[b]{2}{*}{ Identifier type } & \multicolumn{5}{|c|}{ Preweaned pup age } \\
\hline & Attachment year & Week 1 & Week 2 & Week 3 & $\begin{array}{c}\text { Total number } \\
\text { attached }\end{array}$ \\
\hline Bands (16 mm wide) & 2006 & 49 & 40 & 31 & 120 \\
\hline Bands (16 mm wide) & 2007 & 15 & 19 & 17 & 51 \\
\hline Bands (20 mm wide) & 2007 & 13 & 16 & 22 & 51 \\
\hline Temptags $^{\circledR}$ tags & 2007 & 26 & 8 & 14 & 48 \\
\hline Supersmall $^{\circledR}$ tags & 2007 & 29 & 9 & 9 & 47 \\
\hline
\end{tabular}

(4) A single uniquely numbered Jumbotag ${ }^{\circledR}$ can be inserted pre-weaning, but if not removed prior to/at the application of the differently numbered pair of Jumbotags ${ }^{\circledR}$ at weaning, can result in later resighting confusion.

Marker bands were attached to either 'ankle' of unweaned pups. A single tag was attached to either of the two parts of inner-interdigital webbing in the right hind flipper of unweaned pups. Only pups with attending known-age (tagged) mothers were marked and only one marker (band or tag) was applied per pup. Attachment of markers was spread among 30 breeding colony beaches along a $50.4 \mathrm{~km}$ section of the Marion Island coastline. Mothers had been previously double-tagged in each of the hind flippers with colour-coded, uniquely numbered Dal 008 Jumbotags ${ }^{\circledR}$ at weaning. The band/tag number of each unweaned pup was noted in combination with the tag number of the mother. Pup age was estimated from weekly (at least) observations of their mothers following the resighting schedule described in Bester \& Wilkinson (1994). All bands, but not tags, were removed after weaning, and all pups were then tagged with colour-coded uniquely numbered Dal 008 Jumbotags ${ }^{\circledR}$ in the upper, outer interdigital webbing of each hind flipper. We did not remove any of the Supersmall ${ }^{\oplus}$ tags or Temptags ${ }^{\circledR}$, based on the manufacturer's assurance that the tags are of temporary design and are automatically lost as the animal grows and pressure is exerted on the tag.

\section{Data analysis}

The retention of markers over time since attachment is assessed and the marker types with the highest retention rates over the three weeks of suckling were deemed suitable for identifying individual unweaned pups.

\section{RESULTS}

The numbers of bands attached in 2006 and 2007 are given in Table 1.

Attachment effort was constant throughout the study period. A violent storm and heavy seas on 27 October 2007 resulted in several pups disappearing prior to weaning. Differentiation between marker loss and pup loss was impossible for those pups where marker retention was not confirmed prior to the storm. It is assumed that the loss of pups was random, regardless of marker type, with negligible effects on the results. Unweaned, marked pups that were subsequently confirmed dead ( $n=2$; $2006 \& 2007)$ were removed from analysis.

Figure 2 illustrates the loss rates for the four different markers attached during the three-week pre-weaning period. Marker loss was the greatest for one-week-old pups for both the $20 \mathrm{~mm}$ (loss = $61.5 \%$ ) and $16 \mathrm{~mm}$ (loss = 34.4\%) bands (Fig. 2). Marker loss of $16 \mathrm{~mm}$ bands decreased as the pups aged, with only $14.6 \%$ loss for three-weekold pups. Marker loss of $20 \mathrm{~mm}$ bands showed an initial decrease (loss $=18.8 \%$ for two-week-old pups), followed by an increase in band loss for three-week-old pups (31.8\%) (Fig. 2).

Temptags $^{\circledast}(n=48)$ and Supersmall ${ }^{\circledast}(n=47)$ tags were mainly attached on one-week-old pups (Table 1) in 2007. Temptags ${ }^{\circledR}$ were well retained throughout the study, with overall retention at $93.7 \%$. Loss was greatest when attached on three-week-old pups (loss $=14.3 \%$ ). Supersmall ${ }^{\circledR}$ tags were retained at an overall rate of $93.6 \%$. Loss of Supersmall ${ }^{\circledR}$ tags was also greatest when attached on three-week-old pups (loss $=11.1 \%$ ).

In total 109 and 150 pups with known mothers were identified during 2006 and 2007, respectively, representing $43 \%$ (2006) and $60 \%$ (2007) of tagged mothers from Marion Island. 


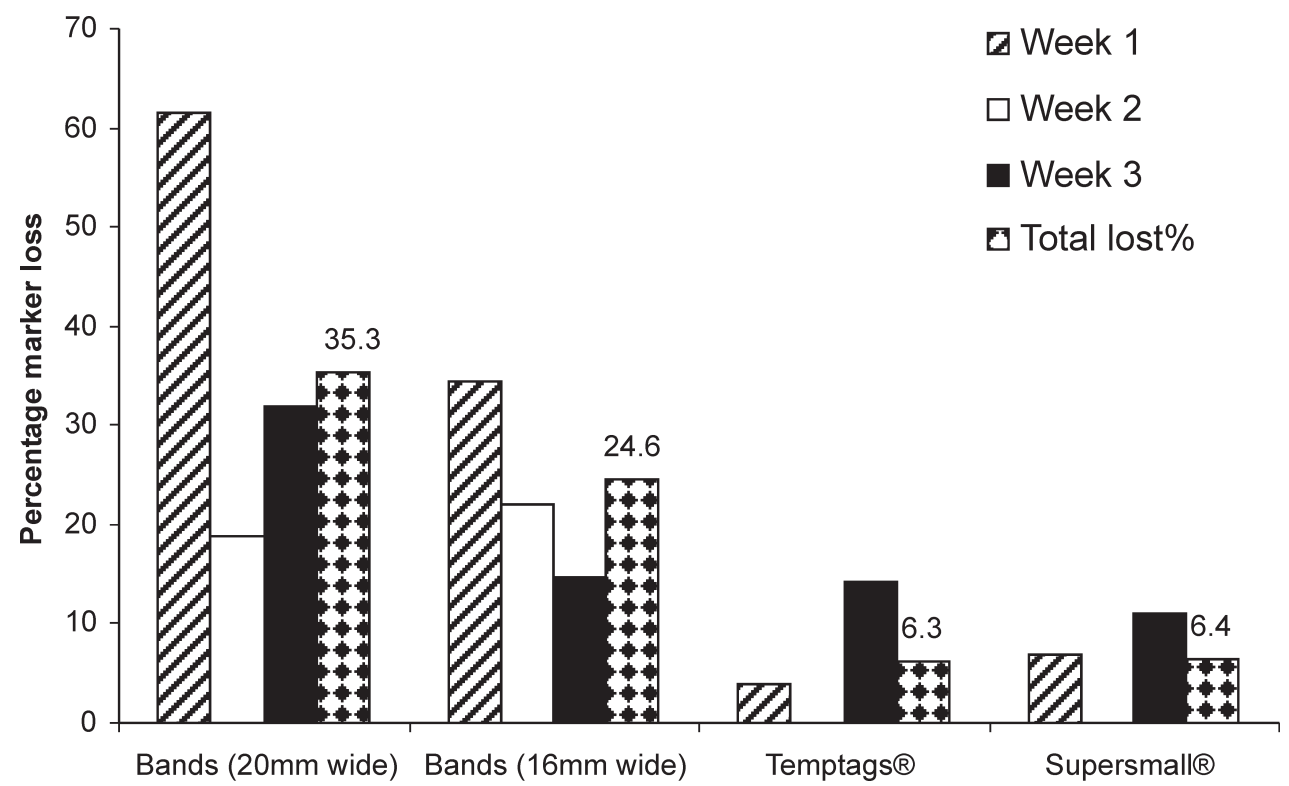

Fig. 2. Percentage marker loss relative to the number attached in each week on unweaned southern elephant seal pups at Marion Island during the three-week pre-weaning period.

Six months after application of Supersmall ${ }^{\circledast}$ tags on pups, only one of seven resighted individuals retained the small tag, while one of 12 resighted animals that had received Temptags ${ }^{\circledR}$ retained its tag.

\section{DISCUSSION}

Marking large numbers of individuals within a population facilitates various studies such as demography, life history, behaviour, dispersal and growth. Individual marking of pinnipeds is relatively easy due to unrestricted access to weaned animals (Bester 1988). Unweaned pups are less accessible for marking due to the gregariousness and aggression of their mothers during the breeding season. Studies requiring a relatively small sample of very young pups with known (tagged) mothers have been achieved by focusing efforts on a single breeding harem/group of animals (e.g. Wilkinson \& Bester 1990; Wilkinson 1991; Wilkinson \& van Aarde 2001). Various pinniped species have been temporarily marked with a variety of materials including the application of dyes, bleach and paint and techniques such as fur clipping (Erickson et al. 1993). These methods are often unsuitable for use on large samples of grouped animals spread over an extensive area due to logistical difficulties such as the quantity of material to be transported, requirement for animals to be dry, time constraints and manpower. The current method, in conjunction with an intensive monitoring programme, allows for the expansion of sample sizes and representativeness within the sample.

We show that of the four methods tested here, marking individual unweaned pups with Temptags ${ }^{\circledR}$ and Supersmall ${ }^{\circledast}$ tags provides an easy, reliable method of temporary marking large numbers of southern elephant seal pups with known-age (tagged) mothers. Animals marked with bands showed poor overall pre-weaning marker retention when compared to animals marked with Temptags ${ }^{\circledR}$ and Supersmall ${ }^{\otimes}$ tags. The poor performance of band markers attached early in the pups' life could be due to a variety of factors. The age of the pup may play a role as one-week-old pups showed higher marker loss (compared to older pups) possibly because their hind flippers were slender and soft, allowing the band to slip off. The band cannot be reduced in diameter for fear of becoming too tight as the pups grow. Alternatively, the durability of the bands might decrease with time as the band is exposed to the corrosive influences of sea water, ultraviolet radiation and general wear and tear brought about by the activity of the pup in a congested harem located on a coarse sandy/ pebbly/boulder strewn substrate. As the pups grow, more pressure is exerted on the fibre, resulting in higher rates of marker loss, especially if the pup has been wearing the marker for some time. Field experience shows that bands take a little 
longer to fit over the 'ankle' of a pup, compared to tagging the pup. Given that pups are not removed from the harem for marking purposes, and considering the aggressive behaviour of adults in these harems, a fast-as-possible incursion of the harem for marking unweaned pups is important.

Flipper tags are not exposed to the same pressures as bands, thus displaying higher overall retention rates than the bands because the tags are protected within the folds of the flipper. The retention rates of tags decreased when attached on older pups; this could be as a result of the thicker interdigital webbing (causing incomplete piercing by the thin tag pin) and stronger flippers (allowing more powerful/vigorous rubbing of the site of new pain stimulus due to tag application) of older pups. Field experience shows that the ease with which Supersmall ${ }^{\circledR}$ tags are applied makes them even more suitable than Temptags ${ }^{\circledR}$ for future use. The fixing pin of the Temptags ${ }^{\oplus}$ occasionally created application difficulties, by dropping out /not aligning properly at the last moment.

We suggest the use of Supersmall ${ }^{\circledast}$ tags as a very effective, quick and inexpensive method of temporarily marking unweaned pups of southern elephant seals. If continued over time, this marking method will allow for more intense exploration of relatedness research topics. This method is likely to be suitable for other phocids breeding in groups or where very young animals need to be marked for future studies.

\section{ACKNOWLEDGEMENTS}

The Department of Environmental Affairs and Tourism supplied logistical support within the South African National Antarctic Programme. The Department of Science and Technology, through the National Research Foundation (South Africa), provided financial support. P.J.N.d.B. benefited from a National Research Foundation Grantholder linked doctoral bursary within the project 'Conservation of Seabirds, Shorebirds and Seals' that funds a consortium of researchers led by L. Underhill of the Animal Demography Unit, Department of Zoology, University of Cape Town. We thank John van den Hoff and lan Wilkinson for their valuable comments and suggestions as reviewers.

\section{REFERENCES}

BESTER, M.N. 1988. Marking and monitoring studies of the Kerguelen stock of southern elephant seals, Mirounga leonina, and their bearing on biological research in the Vestfold Hills. Hydrobiologia 165: 269-277.

BESTER, M.N. \& WILKINSON, I.S. 1994. Population ecology of southern elephant seals at Marion Island. In: B.J. Le Boeuf \& R.M. Laws (Eds), Elephant seals: population ecology, behavior, and physiology (pp. 85-97). University of California Press, Berkeley.

CLOBERT, J., LEBRETON, J-D., ALLAINE, D. \& GAILLARD, J.M. 1994. The estimation of age-specific breeding probabilities from recapture or resightings in vertebrate populations: II. Longitudinal models. Biometrics 50: 375-387.

ERICKSON, A.W., BESTER, M.N. \& LAWS, R.M. 1993. Marking techniques. In: R.M. Laws (Ed.), Antarctic seals: research methods and techniques (pp. 89118). University Press, Cambridge.

LEBRETON, J-D., BURNHAM, K.P., CLOBERT, J. \& ANDERSON, D.R. 1992. Modeling survival and testing biological hypotheses using marked animals: a unified approach with case studies. Ecol. Monogr. 62: 67-118.

MCMAHON, C.R., BESTER, M.N., BURTON, H.R., HINDELL, M.A. \& BRADSHAW, C.J.A. 2005. Population status, trends and a re-examination of the hypotheses explaining the recent declines of the southern elephant seal Mirounga leonina. Mammal Rev. 35: 82-100.

PISTORIUS, P.A., BESTER, M.N., KIRKMAN, S.P. \& BOVENG, P.L. 2000. Evaluation of age- and sexdependent rates of tag loss in southern elephant seals. J. Wildl. Manage. 64: 373-380.

PISTORIUS, P.A., BESTER, M.N., LEWIS, M.N., TAYLOR, F.E., CAMPAGNA, C. \& KIRKMAN, S.P. 2004. Adult female survival, population trend, and the implications of early primiparity in a capital breeder, the southern elephant seal. J. Zool., Lond. 263: 107-119.

SINIFF, D.B., DEMASTER, D.P., HOFMAN, R.J. \& EBERHARDT, L.L. 1977. An analysis of the dynamics of a Weddell seal population. Ecol. Monogr. 47: 319-335.

WILKINSON, I.S. \& BESTER, M.N. 1990. Duration of post-weaning fast and local dispersion in the southern elephant seal, Mirounga leonina, at Marion Island. J. Zool., Lond. 222: 591-600.

WILKINSON, I.S. 1991. Factors affecting reproductive success of southern elephant seals, Mirounga leonina, at Marion Island. Ph.D. thesis, University of Pretoria, Pretoria.

WILKINSON, I.S. \& VAN AARDE, R.J. 2001. Investment in sons and daughters by southern elephant seals, Mirounga leonina, at Marion Island. Mar. Mamm. Sci. 17: 873-887.

Corresponding Editor: J.A.J. Nel 